\title{
Evidence for the founder effect of RET533 as the common Greek and Brazilian ancestor spreading multiple endocrine neoplasia $2 \mathrm{~A}$
}

\author{
Lucas L Cunha', Susan C Lindsey', Maria Inez C França', Leda Sarika ${ }^{3}$, \\ Alexandra Papathoma ${ }^{3}$, Ilda S Kunii', Janete M Cerutti' ${ }^{2}$, Magnus R Dias-da-Silva', \\ Maria Alevizaki ${ }^{3}$ and Rui M B Maciel $^{\mathbf{1}}$ \\ ${ }^{1}$ Departments of Medicine and ${ }^{2}$ Morphology and Genetics, Escola Paulista de Medicina, Universidade \\ Federal de São Paulo, São Paulo, Brazil, and ${ }^{3}$ Endocrine Unit, Department of Medical Therapeutics, \\ School of Medicine, National and Kapodistrian University of Athens, Athens, Greece
}

Correspondence should be addressed to R M B Maciel

Email

rui.maciel@unifesp.br

\begin{abstract}
Objectives: About one-quarter of patients with medullary thyroid cancer (MTC) have inherited disease due to mutations in the RET gene. A rare mutation in exon 8 (G533C) of RET, previously described in a large Brazilian family with MEN2A, also appeared to be clustering in Greece, whereas it was rarely reported in other ethnic groups. The aim of this study was to identify a possible common ancestry between these carriers.

Patients and methods: Twelve RET G533C mutation carriers, four randomly selected from the Brazilian cohort and eight from apparently unrelated Greek families, were studied for a possible common ancestral origin. RET flanking microsatellite markers at chromosome 10q (D10S197, D10S196, D10S1652 and D10S537) were used.

Results: Genomic DNA analysis using these markers showed that many of these apparently unrelated individuals shared a common haplotype indicating a common ancestral origin.

Conclusion: Our data suggest that Brazilian and Greek patients with MTC carrying the G533C mutation in exon 8 of RET gene originate from a common ancestor. Due to historical reasons, we speculate that the more plausible explanation for the origin of this mutation is in Greece.
\end{abstract}

\section{Introduction}

More than $25 \%$ of medullary carcinoma patients (MTC) have familial disease, which is due to germ line mutations of the RET gene. The clinical presentation varies according to the type of RET mutation. After the routine application of genetic analysis in all MTC cases (1), it became apparent that some apparently sporadic cases were in fact familial as they carried a RET mutation. Furthermore, a wider distribution of mutations across the RET gene was identified, which were different from those originally described. In this context, we recently described a large family with medullary thyroid carcinoma (MTC) carrying a missense mutation in exon 8 of RET, which corresponds
C 2017 European Society of Endocrinology Printed in Great Britain to a glycine-to-cysteine substitution at codon 533 (2); this was later confirmed to be MEN2A. This family comprises 728 members of Caucasian origin with ancestors from Catalunia, Spain, who immigrated to Brazil at the end of the 19th century. Most of the family members live in Southeastern Brazil and have been followed at an outpatient Endocrine Unit either in Vitoria or São Paulo by the same team of physicians for over fifteen years. During this long-term follow-up, molecular and clinical characteristics of these patients have been described in detail $(3,4)$. However, the ancestry related to the origin of G533C RET mutation remains to be elucidated. 
A

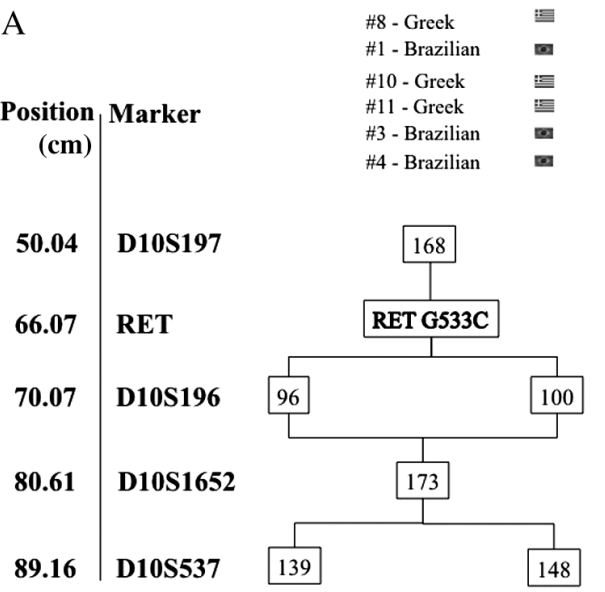

B

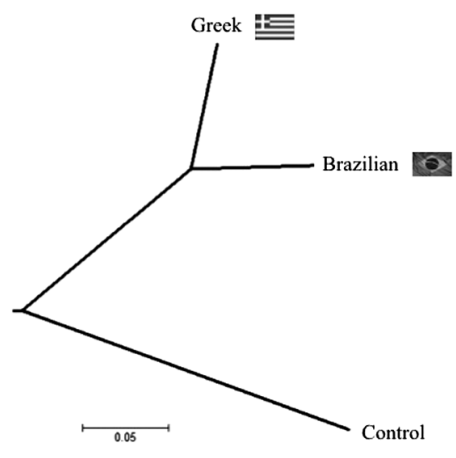

Figure 1

(A) Schematic distribution of RET microsatellite markers in representative family members of apparently unrelated kindreds from Brazil and Greece. Microsatellite markers D10S197, D10S196, D10S1652 and D10S537, and their distance in $\mathrm{cm}$, distributed throughout RET genomic region as haplotype analysis. (B) Phylogenetic tree of Brazilian and Greek families and controls.
In 2007, Bethanis et al. reported a Greek patient with MEN 2A harboring the same RET G533C mutation (5). A few years later, Sarika et al. identified this mutation in 10 out of 129 patients with apparently sporadic medullary thyroid carcinoma in Greece (6). Gathering these results, we hypothesized whether Brazilian and Greek patients carrying the same RET mutation could share a common ancestor.

We proceeded with the investigation of putative founder effect as a point of coalescence between Brazilian and Greek affected families.

\section{Patients and methods}

Twelve patients with the G533C RET mutation were enrolled in the study: 4 randomly selected from the Brazilian cohort and 8 randomly selected from apparently unrelated Greek families and followed at the Endocrine Unit of Athens University Medical School (Athens, Greece). A control group comprising 29 unrelated thyroid-healthy Brazilian individuals was also studied. Blood samples were obtained from all participants, and all laboratory procedures were performed at the Laboratory of Molecular and Translational Endocrinology at the Federal University of Sao Paulo - UNIFESP, Brazil. The study protocol was approved by the internal review board of UNIFESP (São Paulo, Brazil) and University of Athens (Athens, Greece). All patients received genetic counseling before and after RET testing.

Genomic DNA was extracted from peripheral-blood leucocytes as previously reported (7). Haplotype analysis using four RET flanking microsatellite markers (D10S197, D10S196, D10S1652 and D10S537) was performed, as described by Qi et al. (8), to track a founder effect. The first marker was placed at position $50.04 \mathrm{~cm}$ and the other three at positions 70.07, 80.61 and $89.16 \mathrm{~cm}$ (Fig. 1A). The chromosome map distances were derived from the deCODE map (URL:http://www.ncbi.nlm.nih.gov/probe).

Haplotypes of patients and controls were reconstructed using the statistical software package PHASE, version 2.1 (http://stephenslab.uchicago.edu/software.html) (9). We constructed the phylogenetic tree of the studied families with POPTREE2 software by estimating the genetic distance between them (10). Chi-square test was used to yield differences in allele distribution among Greek patients, Brazilian patients and Brazilian controls.

Table 1 Clinical characteristics of the cohort of G533C patients.

\begin{tabular}{|c|c|c|c|c|c|}
\hline $\begin{array}{l}\text { Patient } \\
\text { number }\end{array}$ & Origin & $\begin{array}{c}\text { Age at } \\
\text { diagnosis } \\
\text { (years) }\end{array}$ & Gender & $\begin{array}{l}\text { pTNM } \\
\text { staging }\end{array}$ & $\begin{array}{l}\text { Status at the } \\
\text { last follow-up } \\
\text { visit }\end{array}$ \\
\hline 1 & Brazil & 57 & $\mathrm{~F}$ & T1N0Mx & NED \\
\hline 2 & Brazil & 44 & $\mathrm{~F}$ & T2N1aMx & NED \\
\hline 3 & Brazil & 33 & $\mathrm{M}$ & No MTC & NED \\
\hline 4 & Brazil & 53 & $\mathrm{M}$ & T3N1aM0 & NED \\
\hline 5 & Greece & 36 & $\mathrm{~F}$ & T1N0M0 & NED \\
\hline 6 & Greece & 34 & $\mathrm{~F}$ & T1bN0M0 & NED \\
\hline 7 & Greece & 55 & $\mathrm{M}$ & T1N0M0 & NED \\
\hline 8 & Greece & 37 & $\mathrm{M}$ & T1N0M0 & NED \\
\hline 9 & Greece & 35 & $\mathrm{~F}$ & T1N0M0 & NED \\
\hline 10 & Greece & 35 & $\mathrm{~F}$ & T1N0M0 & NED \\
\hline 11 & Greece & 24 & $\mathrm{~F}$ & T3N1aM0 & NED \\
\hline 12 & Greece & 50 & $\mathrm{~F}$ & T1N0M0 & NED \\
\hline
\end{tabular}

NED, no evidence of disease. 
Table 2 Polymorphic microsatellite markers and allele frequency in Brazilian and Greek patients with medullary thyroid carcinoma bearing the RET G533C mutation.

\begin{tabular}{|c|c|c|c|c|c|c|}
\hline \multirow[b]{2}{*}{ Marker } & \multirow[b]{2}{*}{ Allele } & \multicolumn{2}{|c|}{$\begin{array}{c}\text { RET G533C } \\
\text { Brazilian patients }\end{array}$} & \multicolumn{2}{|c|}{$\begin{array}{l}\text { RET G533C Greek } \\
\text { patients }\end{array}$} & \multirow[b]{2}{*}{$P$ value } \\
\hline & & $n$ & $\%$ & $n$ & $\%$ & \\
\hline \multirow{3}{*}{ D10S197 } & 162 & 0 & 0 & 3 & 37.5 & 0.223 \\
\hline & 166 & 0 & 0 & 1 & 12.5 & \\
\hline & 168 & 4 & 100 & 4 & 50 & \\
\hline \multirow[t]{3}{*}{ D10S196 } & 96 & 3 & 75 & 4 & 50 & 0.634 \\
\hline & 98 & 0 & 0 & 1 & 12.5 & \\
\hline & 100 & 1 & 25 & 3 & 37.5 & \\
\hline \multirow{4}{*}{ D10S1652 } & 157 & 1 & 25 & 0 & 0 & 0.312 \\
\hline & 166 & 0 & 0 & 1 & 12.5 & \\
\hline & 170 & 0 & 0 & 2 & 25 & \\
\hline & 173 & 3 & 75 & 5 & 62.5 & \\
\hline \multirow[t]{5}{*}{ D10S537 } & 139 & 2 & 50 & 1 & 12.5 & 0.262 \\
\hline & 144 & 1 & 25 & 0 & 0 & \\
\hline & 148 & 1 & 25 & 5 & 62.5 & \\
\hline & 152 & 0 & 0 & 1 & 12.5 & \\
\hline & 154 & 0 & 0 & 1 & 12.5 & \\
\hline
\end{tabular}

GenePop was used to perform Hardy-Weinberg exact test (11), and all loci were in Hardy-Weinberg equilibrium.

\section{Results}

This study included 8 Greek patients ( 2 men and 6 women) and 4 Brazilian patients ( 2 men and 2 women). Clinical and biochemical data of these patients are summarized in Table 1. As can be seen from the table, all the examined cases had excellent long-term follow-up compatible with the relatively mild phenotype that has already been reported for carriers of this mutation (12). Furthermore, the age at presentation was in all cases relatively late.

Four MTC patients (3 from Greece and one from Brazil) shared a common haplotype (D10S197-RETD10S196-D10S1652: 168-RETG533C-100-173-148, Fig. 1A and Table 2), which was not seen in chromosomes bearing wild-type alleles $(P<0.005)$. In fact, Brazilian patients presented similar distribution of RET polymorphic microsatellite markers compared to Greek patients, suggesting that patients from both nationalities may share a unique genetic signature (Table 2). When comparing Brazilian and Greek affected patients to the control group, we observed a different distribution of D10S197 $(P=0.016), \mathrm{D} 10 \mathrm{~S} 196(P=0.042), \mathrm{D} 10 \mathrm{~S} 1652(P<0.001)$ and D10S537 alleles $(P=0.003$; Table 3$)$. These results reveal a genetic progenitor similarity between Brazilian and Greek RET G533C patients regarding RET flanking regions that was not observed in unrelated thyroid-healthy controls.

According to the analysis of the phylogenetic tree of the MTC patients and controls, Brazilian and Greek patients pertained to a common root, corresponding to a putative most recent common ancestor (Fig. 1B). As a matter of fact, the control group shared reduced genetic similarity with the MTC patients.

\section{Discussion}

After the original identification that the exon 8 G533C RET mutation is associated with inherited MTC in our large Brazilian pedigree, there followed very few relative reports from the Mediterranean region and especially from Greece. Interestingly, the one family harboring this mutation in the USA proved to be of Greek ethnic origin (13). Our data suggest that Brazilian patients with MTC caused by the G533C RET mutation have an ancestor common to the Greek patients that share the same RET genotype. Indeed, by tracking the founder effect, we brought scientific shreds of evidence to this sense. Probably, the G533C mutation observed in Brazilian patients, originally from Catalunia, Spain, was settled by a migratory movement in Europe, either from Greece or from those same who established the Greek population.

Since ancient times, more than thirty Greek citystates had several colonies over the Mediterranean Sea,

Table 3 Comparison of RET haplotype frequency among Brazilian and Greek RET533 patients with thyroid-healthy controls.

\begin{tabular}{|c|c|c|c|c|c|c|c|}
\hline Marker & Allele & $\begin{array}{c}\text { RET G533C Brazilian } \\
\text { patients }\end{array}$ & RET G533C Greek patients & Thyroid-healthy controls & $P$ value $^{\mathrm{a}}$ & P value $^{\text {b }}$ & $P$ value $^{c}$ \\
\hline \multirow[t]{2}{*}{ D10S197 } & 168 & 4 & 4 & 18 & 0.013 & 0.424 & 0.016 \\
\hline & Other alleles & 0 & 8 & 40 & & & \\
\hline \multirow[t]{2}{*}{ D10S196 } & 96 & 3 & 4 & 14 & 0.059 & 0.199 & 0.042 \\
\hline & Other alleles & 1 & 4 & 44 & & & \\
\hline \multirow[t]{2}{*}{ D10S1652 } & 173 & 3 & 5 & 1 & $<0.001$ & $<0.001$ & $<0.001$ \\
\hline & Other alleles & 1 & 3 & 57 & & & \\
\hline \multirow[t]{2}{*}{ D10S537 } & 148 & 1 & 5 & 8 & 0.472 & 0.004 & 0.003 \\
\hline & Other alleles & 3 & 3 & 50 & & & \\
\hline
\end{tabular}

aBrazilian patients vs controls; ' ${ }^{b}$ Greek patients vs controls; 'Brazilian patients vs Greek patients vs controls. 
including in the Iberian Peninsula, where Catalunia is located (14). In our first description of the G533C RET mutation, we speculated that 'this large family has a Caucasian background from Catalunia, and it is conceivable that relatives living in Europe might also bear the same mutation; hence, it is likely to address a founder effect from Spain, and it is feasible that other relatives also migrated to other countries by the time the ancestor moved to Brazil at the end of the 19th century' (2).

The fact that Brazilian (from Catalunia, Spain) and Greek patients have a common ancestor is fascinating and suggests that, historically, the more plausible explanation for the origin of this mutation is in Greece as Greek migratory currents have occurred in the Mediterranean Sea for many centuries; furthermore, the substantial proportion of the G533C RET mutation among the hereditary MTC patients in Greece reinforces this hypothesis (6).

It is worth noting that the world is a melting pot, in which our genetically heterogeneous population can be described as a complex fusion of ethnicities, nationalities and cultures. In this scenario, cultural assimilation in the setting of immigration is important not only for the maintenance of national unity but also for the understanding of the genetic distribution of deleterious alleles. This ethnographic consideration highlights the impact of the present study on public health.

Declaration of interest

The authors declare that there is no conflict of interest that could be perceived as prejudicing the impartiality of the research reported.

Funding

The authors' research was supported by grants from the São Paulo State Research Foundation/FAPESP (2006/60402-1 and 2010/51547-1 to R M B M and M R D S and 2014/06570-6 to J M C) and from the Fleury Group (12518). S C L received a research fellowship grant from FAPESP (2009/50575-4). R M $B M$ is an investigator of the Fleury Group. J M C is an investigator of the Brazilian National Research Council (CNPq).

\section{Author contribution statement}

Lucas L Cunha: Collection and assembly of data, data analysis and interpretation and manuscript writing; Susan C Lindsey: Clinical data analysis, interpretation and manuscript writing; Maria Inez C França: Provision of study patients; Leda Sarika: Provision of study patients, clinical data analysis and interpretation; Alexandra Papathoma: Technical support; Ilda S Kunii: Technical support; Janete M Cerutti: Data analysis and interpretation and manuscript writing; Magnus $\mathrm{R}$ Dias-da-Silva: Design, data analysis and interpretation and manuscript writing; Maria
Alevizaki: Conception and design and manuscript writing; Rui M B Maciel: Conception and design and manuscript writing.

\section{Acknowledgements}

The authors thank the team from the Laboratory of Molecular and Translational Endocrinology, especially Dr Cléber Camacho.

\section{References}

1 Elisei R, Alevizaki M, Conte-Devolx B, Frank-Raue K, Leite V \& Williams GR. 2012 European thyroid association guidelines for genetic testing and its clinical consequences in medullary thyroid cancer. European Thyroid Journal $20131216-231$. (doi:10.1159/000346174)

2 Da Silva AM, Maciel RM, Da Silva MR, Toledo SR, De Carvalho MB \& Cerutti JM. A novel germ-line point mutation in RET exon 8 (Gly(533)Cys) in a large kindred with familial medullary thyroid carcinoma. Journal of Clinical Endocrinology and Metabolism $2003 \mathbf{8 8}$ 5438-5443. (doi:10.1210/jc.2003-030997)

3 Oliveira MN, Hemerly JP, Bastos AU, Tamanaha R, Latini FR, Camacho CP, Impellizzeri A, Maciel RM \& Cerutti JM. The RET p.G533C mutation confers predisposition to multiple endocrine neoplasia type $2 \mathrm{~A}$ in a Brazilian kindred and is able to induce a malignant phenotype in vitro and in vivo. Thyroid 201121 975-985 (doi:10.1089/thy.2010.0190)

4 Signorini PS, Franca MI, Camacho CP, Lindsey SC, Valente FO, Kasamatsu TS, Machado AL, Salim CP, Delcelo R, Hoff AO et al. A ten-year clinical update of a large RET p.Gly533Cys kindred with medullary thyroid carcinoma emphasizes the need for an individualized assessment of affected relatives. Clinical Endocrinology 201480 235-245. (doi:10.1111/cen.12264)

5 Bethanis S, Koutsodontis G, Palouka T, Avgoustis C, Yannoukakos D, Bei T, Papadopoulos S, Linos D \& Tsagarakis S. A newly detected mutation of the RET protooncogene in exon 8 as a cause of multiple endocrine neoplasia type 2A. Hormones 20076 152-156. (doi:10.14310/horm.2002.1111011)

6 Sarika HL, Papathoma A, Garofalaki M, Vasileiou V, Vlassopoulou B, Anastasiou E \& Alevizaki M. High prevalence of exon 8 G533C mutation in apparently sporadic medullary thyroid carcinoma in Greece. Clinical Endocrinology 201277 857-862. (doi:10.1111/j.13652265.2012.04462.x)

7 Kizys MM, Cardoso MG, Lindsey SC, Harada MY, Soares FA, Melo MC, Montoya MZ, Kasamatsu TS, Kunii IS, Giannocco G et al. Optimizing nucleic acid extraction from thyroid fine-needle aspiration cells in stained slides, formalin-fixed/paraffin-embedded tissues, and long-term stored blood samples. Arquivos Brasileiros de Endocrinologia e Metabologia 201256 618-626. (doi:10.1590/S000427302012000900004)

8 Qi XP, Ma JM, Du ZF, Ying RB, Fei J, Jin HY, Han JS, Wang JQ, Chen XL, Chen CY et al. RET germline mutations identified by exome sequencing in a Chinese multiple endocrine neoplasia type 2A/familial medullary thyroid carcinoma family. PLOS ONE 20116 e20353. (doi:10.1371/journal.pone.0020353)

9 Stephens M \& Scheet P. Accounting for decay of linkage disequilibrium in haplotype inference and missing-data imputation. American Journal of Human Genetics 200576 449-462. (doi:10.1086/428594)

10 Latter BD. Selection in finite populations with multiple alleles. 3. Genetic divergence with centripetal selection and mutation. Genetics $197270475-490$. 
11 Rousset F. Genepop'007: a complete re-implementation of the genepop software for Windows and Linux. Molecular Ecology Resources 20088 103-106. (doi:10.1111/j.1471-8286.2007.01931.x)

12 Wells SA Jr, Asa SL, Dralle H, Elisei R, Evans DB, Gagel RF, Lee N, Machens A, Moley JF, Pacini F et al. Revised American Thyroid Association guidelines for the management of medullary thyroid carcinoma. Thyroid 201525 567-610. (doi:10.1089/thy.2014.0335)
13 Castro MR, Thomas BC, Richards ML, Zhang J \& Morris JC. Multiple endocrine neoplasia type 2A due to an exon 8 (G533C) mutation in a large North American kindred. Thyroid 201323 1547-1552. (doi:10.1089/thy.2012.0599)

14 Braudel F. The Mediterranean and the Mediterranean World in the Age of Philip II. Berkeley, California, USA: University of California Press, 1995.

Received 13 December 2016

Accepted 30 January 2017 